\title{
A statistical analysis of insurance damage claims related to rainfall extremes
}

\author{
M. H. Spekkers ${ }^{1}$, M. Kok ${ }^{2}$, F. H. L. R. Clemens ${ }^{1}$, and J. A. E. ten Veldhuis ${ }^{1}$ \\ ${ }^{1}$ Delft University of Technology, Department of Water Management, Delft, the Netherlands \\ ${ }^{2}$ Delft University of Technology, Department of Hydraulic Engineering, Delft, the Netherlands \\ Correspondence to: M. H. Spekkers (m.h.spekkers@tudelft.nl)
}

Received: 24 September 2012 - Published in Hydrol. Earth Syst. Sci. Discuss.: 11 October 2012

Revised: 17 January 2013 - Accepted: 15 February 2013 - Published: 4 March 2013

\begin{abstract}
In this paper, a database of water-related insurance damage claims related to private properties and content was analysed. The aim was to investigate whether the probability of occurrence of rainfall-related damage was associated with the intensity of rainfall. Rainfall data were used for the period of 2003-2009 in the Netherlands based on a network of 33 automatic rain gauges operated by the Royal Netherlands Meteorological Institute. Insurance damage data were aggregated to areas within $10-\mathrm{km}$ range of the rain gauges. Through a logistic regression model, high claim numbers were linked to maximum rainfall intensities, with rainfall intensity based on 10-min to 4-h time windows. Rainfall intensity proved to be a significant damage predictor; however, the explained variance, approximated by a pseudo- $R^{2}$ statistic, was at most $34 \%$ for property damage and at most $30 \%$ for content damage. When directly comparing predicted and observed values, the model was able to predict $5-17 \%$ more cases correctly compared to a random prediction. No important differences were found between relations with property and content damage data. A considerable fraction of the variance is left unexplained, which emphasizes the need to study damage generating mechanisms and additional explanatory variables.
\end{abstract}

\section{Introduction}

In the autumn of 1998 extreme rainfall caused around 410 million euros (1998 value) of direct damages to households, agriculture and industries in the Netherlands. Damage experts from the Dutch insurance sector identified a total number of 10660 agricultural companies, 2470 buildings, 1220 other companies and 350 governmental agencies as being damaged by rainwater (Jak and Kok, 2000). The rainfall event with an associated return period of about $125 \mathrm{yr}$ resulted in flooding of areas before rainwater was able to enter natural or engineered drainage systems. This type of floods is commonly known as pluvial flooding (e.g. Hurford et al., 2012a; Blanc et al., 2012; Falconer et al., 2009). Other severe events that are well documented are the summer floods of 2007 across the UK, for example in the City of Hull, that are believed to be for a great deal related to pluvial flooding (Pitt, 2008; Coulthard and Frostick, 2010), and the 2004 and 2006 floods in Heywood, Greater Manchester (Douglas et al., 2010). These events are just a few of the many examples that illustrate the serious consequences of high-intensity rainfall. But also minor events with relatively small flood volumes and extensions can produce considerable damage in the long run due to their high frequency of occurrence (Freni et al., 2010; Ten Veldhuis, 2011). The aforementioned events have demonstrated that pluvial floods often occur at much smaller ranges of spatial and temporal scales than fluvial and coastal floods.

An increasing number of authors have acknowledged that a lack of data availability and quality have been important limitations in quantitative flood damage estimations (e.g. Freni et al., 2010; Merz et al., 2004; Hurford et al., 2012b). In the absence of damage data, a common approach in flood damage estimation is to combine simulated flood depths and/or flow velocities and stage-damage curves (e.g. Ernst et al., 2008; Jonkman et al., 2008; Pistrika and Jonkman, 2009; De Moel and Aerts, 2011; Middelmann-Fernandes, 2010). The stage-damage curves are usually related to direct damages occurring in large catchments and are derived 
through synthetic and/or empirical approaches. Only few studies have focused on modelling damages of pluvial floods related to the malfunctioning of urban drainage systems (e.g. Zhou et al., 2012a).

Insurance databases are a promising source for flood damage data. These databases often contain many claim records that have been collected continuously in time. Disadvantages are the restricted access and the limited recordings of process information, such as flood depth and extent measurements, details on damage causes, and building information (Elmer et al., 2010; Thieken, 2011; Zhou et al., 2012b).

A few recent studies have analysed insurance data related to pluvial floods. Freni et al. (2010) conducted a damage assessment based on the outcomes of a simple and a detailed hydrodynamic model in combination with stagedamage functions derived from around 600 insurance damage claims and water depth measurements for a case study in Palermo, Italy. They concluded that uncertainty in stagedamage function (40-50\% of average value) was higher than the accuracy gained by adopting a detailed hydrodynamic model. In another study, 1000 insurance damage claims related to sewer surcharging for the case of Aarhus, Denmark, showed that costs per claim were not explained by rainfall (Zhou et al., 2012b). They did find a significant relationship between rainfall and total costs per day. These studies confirmed the need to obtain accurate damage data to further investigate costs of pluvial floods.

In this study, data from an insurance database containing $20 \mathrm{yr}$ of water-related claims for private properties and contents in the Netherlands, provided by the Dutch Association of Insurers, were analysed. The analysis built on earlier work by the Dutch Association of Insurers, where relationships between rainfall and claim data were studied at a regional scale (Ririassa and Hoen, 2010). Using simple linear regression, they found significant relationships between the total amount of damage in a province (roughly $2500-3500 \mathrm{~km}^{2}$ in size) and hourly rainfall data (one or two rain gauges per province), but the explained variance was low (4\% for content and $12 \%$ for property). It can be argued that, given the size of a province and the limited number of rain gauges used, the model does not account for variations in damage caused by local rainfall, whilst local convective rainfall is probably an important contributor to damage. The aim of this study was to investigate whether high numbers of damage claims are associated with high rainfall intensities, considering rainfall at scales most closely related to functioning of urban drainage systems. In an exploratory study, various damage statistics were correlated with rainfall intensity and the strongest correlation was found between rainfall intensity and the number of damage claims. Rainfall intensity was selected to characterise rainfall events as it was hypothesized to be the most critical rainfall characteristic in relation to damage generating mechanisms such as overloading of sewer systems. Separate relationships were analysed between rainfall data and property damage data as well as content damage data, through statistical analysis. A better understanding of relationships between rainfall extremes and floods is useful in the development of, for example, warning systems for pluvial floods (Hurford et al., 2012a; Parker et al., 2011; Priest et al., 2011).

This paper is structured as follows. In Sect. 2 data sources as well as the statistical model to link rainfall and insurance damage data are described. Results of the statistical analysis are discussed in Sect. 3, as well as the significance of predictor variables and the model performance, followed by a discussion in Sect. 4. Conclusions and recommendations are summarized in Sect. 5.

\section{Methodology}

\subsection{Rainfall data}

Rainfall data are based on two networks of rain gauges held by the Royal Netherlands Meteorological Institute (KNMI): a network of 300+ manual rain gauges (see Fig. 1, triangular markers) and a network of 33 automatic rain gauges (solid circles). The temporal resolution of the automatic network is $10 \mathrm{~min}$, and the spatial density is about 1 station every $1000 \mathrm{~km}^{2}$ (see also Table 1), with most of the rain gauges located in rural areas or close to city boundaries. The manual network measures daily volumes based on 08:00 UTC08:00 UTC intervals. The spatial density of the manual network is about 1 station every $100 \mathrm{~km}^{2}$. All gauge data have been extensively validated by KNMI (KNMI, 2000).

\subsection{Insurance data}

The insurance databases cover water-related damages to private properties and content in the Netherlands and are summarized in Table 1. Data related to property and content damage are available from 1986 until 2009 and from 1992 until 2009 respectively. The database consists of data from a number of large insurance companies in the Netherlands, covering about $20-30 \%$ of the Dutch market related to property and content policies.

House owners can insure both property and content; tenants can only insure content, while the rented property is considered a commercial building. Commercial buildings are covered in a separate database that is not used in this study. Table 2 lists the key characteristics of the insurance databases. All values are in 2009 euros. Every value associated with a year before 2009 was adjusted for inflation using the consumer price index (Statistics Netherlands, 2012).

Water-related damages can be divided into two groups: (1) non-rainfall-related damages and (2) rainfall-related damages. Examples in the first group are bursts of water supply pipes and leakages of washing machines. Examples in the second group are leakages of roofs and flooding from sewer systems or regional watercourses. This distinction is not explicitly made in the data provided by insurance companies. 
Table 1. Summary of rainfall and insurance data sources.

\begin{tabular}{lllll}
\hline Data source & Temporal resolution & Spatial resolution & Availability & Records \\
\hline Manual rain gauge network & daily volumes & $\approx 1 / 100 \mathrm{~km}^{2}$ & 1950 -today & \\
Automatic rain gauge network & 10 -min volumes & $\approx 1 / 1000 \mathrm{~km}^{2}$ & 2003-today & \\
Property damage database & by day & district level & $1986-2009$ & $\approx 300000$ \\
Content damage database & by day & district level & $1992-2009$ & $\approx 270000$ \\
\hline
\end{tabular}

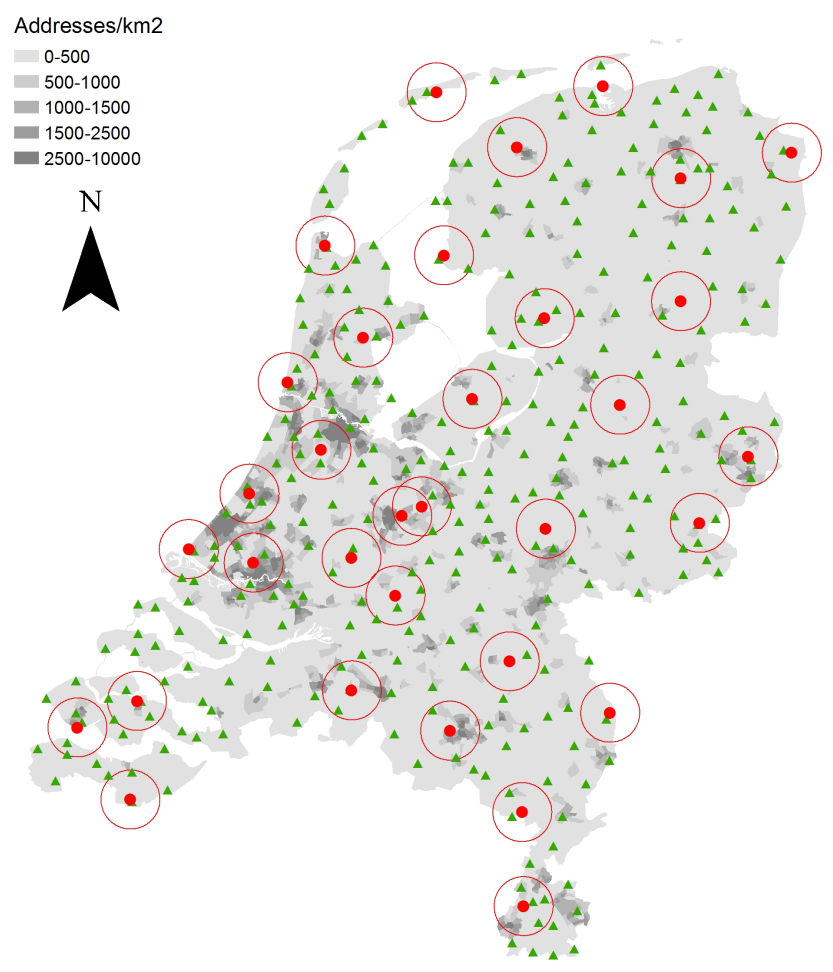

Fig. 1. Locations of 33 automatic rain gauges (solid circles) and $300+$ manual rain gauges (triangular markers) and the area within a $10-\mathrm{km}$ radius of automatic rain gauges (open circles). Urban density (addresses $/ \mathrm{km}^{2}$ ) is presented in grey scales.

Insurance companies use different systems to classify claims, and the quality with which claims are assigned to groups varies between companies.

Damage due to pluvial flooding is included in most of the insurance policies after 2000 following advice issued by the Dutch Association of Insurers (Ministry of Transport, Public Works and Water Management, 2003). Damage due to pluvial floods should be directly and solely related to local extreme rainfall for a claim to be accepted. Flooding from rivers, sea or groundwater is not commonly insured in the Netherlands, and therefore if pluvial flooding coincides with other flood types, the damage is not insured. Rainfall is considered "extreme" when "rainfall intensity is higher than $40 \mathrm{~mm}$ in $24 \mathrm{~h}, 53 \mathrm{~mm}$ in $48 \mathrm{~h}$ or $67 \mathrm{~mm}$ in $72 \mathrm{~h}$ at or near the location of the damaged property", without "near" being precisely defined. The intensities are associated with occurrence
Table 2. Key characteristics of insurance databases held by the Dutch Association of Insurers for the period 2003-2009.

\begin{tabular}{rllllll}
\hline & \multirow{2}{*}{$\begin{array}{l}\text { Number of } \\
\text { policies in } \\
\text { millions per year }\end{array}$} & $\begin{array}{l}\text { Number } \\
\text { of } \\
\text { claims }\end{array}$ & & \multicolumn{4}{c}{ Damage per claim in euros } \\
\cline { 4 - 7 } & & Mean & P10 & Median & P90 \\
\hline Property & 0.9 & 111000 & 1486 & 205 & 825 & 3140 \\
Content & 1.8 & 96000 & 1015 & 144 & 564 & 2202 \\
\hline
\end{tabular}

frequencies of once every 3 to $7 \mathrm{yr}$ in the Netherlands. It is unclear how and to what extent fulfilment of this requirement is examined by the insurance companies. Upon further inquiry, companies have indicated that detailed rainfall data to examine individual cases of local rainfall are usually lacking.

The insurance database consists of four sub-databases: (1) a damage claim database with records related to property; (2) a damage claim database with records related to building content; (3) a database with policy holder information related to property insurances; and (4) a database with policy holder information related to content insurances. The databases with policy holder information related to content and property are separate databases, and it is impossible to link them. Therefore, content and property claims cannot be related to a single household. The variables that are included in the database are listed in Table 3. The address of the insured household is available at 4-position district (i.e. neighbourhood) level. Typical surface areas of districts are $1-5 \mathrm{~km}^{2}$ for urban areas and $10-50 \mathrm{~km}^{2}$ for rural areas. Recorded damages include the costs of cleaning, drying and replacing materials and objects and the costs of temporarily rehousing of people. For the analysis in this paper, it is assumed that the number of insurance policies is constant during one year. In case an insurance policy is only active for a part of the year, the insurance policy is counted proportionally for that year. Duplicate records were removed, as well as records with missing or incorrect date, location or damage value (around $6 \%$ of the original database). Records with damage value equal to zero were also removed (around $1 \%$ of the records), as these are damage claims that did not meet the policy conditions. First and last day of the month were excluded as they, in a few cases, showed unrealistically high claim numbers compared to other days. These days are probably due to software defaults when exact damage date was unknown or not entered by the insurer's employee. 
Table 3. A brief overview of variables recorded in insurance databases held by the Dutch Association of Insurers. The damage claim records can be linked to the policy holder information through the policy ID key.

\begin{tabular}{ll}
\hline Damage claim records & Policy holder information \\
\hline Damage value claimed & Type of building \\
Damage value paid out & Policy coverage \\
Date damage occurred & Start date of policy \\
Damage cause & End date of policy \\
Policy ID key & Insured sum of property \\
& Insured sum of content \\
& 4-position district code \\
& Policy ID key \\
\hline
\end{tabular}

\subsection{Aggregating rainfall and insurance data}

This study covers data from April 2003 to 2009. Insurance damage data were selected within a $10-\mathrm{km}$ radius from the automatic rain gauges based on the distance between the district's centroid and its nearest automatic rain gauge (version shapefile of districts: March 2011). It is assumed that rainfall measured at the rain gauges is uniformly distributed in the rain gauge area. Rain gauge data are generally assumed to be representative within a range of several kilometers. Several ranges were tested and a $10-\mathrm{km}$ range proved to be the best compromise between distance from rain gauges and number of data covered. In Overeem et al. (2011) it is expected that the decorrelation distance for Dutch rainfall events is larger than $15 \mathrm{~km}$. They refer to a study by Berne et al. (2004) where a decorrelation distance of $15 \mathrm{~km}$ was found for typical intense Mediterranean rain events, which are on average more intense and more convective compared to rainfall events in the Netherlands. This justifies selecting the claims within $10 \mathrm{~km}$ from a rain gauge. Figure 2 shows two rain gauges and their neighbouring districts. Insurance data were converted to count data: the number of water-related claims $k_{i}$ and number of insured households $K_{i}$ were aggregated by day and by rain gauge area. The subscript $i$ denotes the index of the observation. The number of insured households per rain gauge area ranges from around 300 to 55000 for property insurance and from around 300 to 120000 for content insurance. The higher number of content insurances is explained by the fact that property insurance only concerns house owners, whereas content insurance concerns both house owners and tenants. Observations with less than 5000 households were filtered out as they were found to be very sensitive to errors in data. The maximum rainfall intensity $I_{i, z}$ is determined for each day and rain gauge area, where subscript $z$ denotes the length in minutes of the moving time window, for $z$ values 10 (original data), 20, 30, 40, $50,60,70,80,90,120,180,240$ or $480 \mathrm{~min}$.

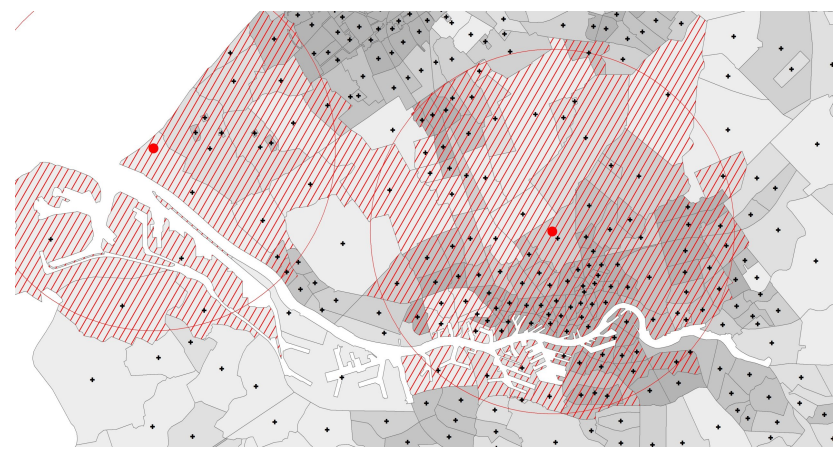

Fig. 2. Example to illustrate the subsetting of insurance data. The two red dots are rain gauges and the open circles the rain gauge areas. The black crosses are the centroids of the districts. The shaded areas are the districts that have been subsetted.

\subsection{Distinguishing rainfall-related and non-rainfall-related events}

The distinction between non-rainfall-related and rainfallrelated claims is not explicitly made in the data provided by insurance companies. Non-rainfall-related claims occur throughout the year, whereas rainfall-related claims are clustered on wet days. Consequently, a high number of claims in a rain gauge region on a particular day is more likely to be associated with rainfall. In the remainder of this paper, these observations are labelled as "damage events".

The number of claims that can be expected on dry days was estimated based on claims recorded on dry days in 10$\mathrm{km}$ ranges from the network of $300+$ manual rain gauges, in order to obtain an independent estimate of the data associated with gauges in the automatic network. Observations were only selected in case of two subsequent dry days, because the daily volumes recorded by manual gauges are based on 08:00 UTC-08:00 UTC intervals. It was found that the number of non-rainfall-related claims is well described as a binomially distributed random variable:

$k_{i} \sim B\left(K_{i}, \zeta\right)$,

where $K_{i}$ is the number of insured households and $\zeta$ the probability that an individual, insured household will have a non-rainfall-related claim on a day. It is assumed that $\zeta$ is constant in both time and space. Best fits with data were found for $\zeta=3.2 \times 10^{-5}$ (property data) and $\zeta=1.3 \times 10^{-5}$ (content data). The probability of obtaining $y$ claims at least as extreme as $k_{i}$, the one observed, given the number of insured households $K_{i}$ (i.e. $p$ value) is therefore

$\operatorname{Pr}\left(y \geq k_{i} \mid K_{i}\right)=1-\sum_{y=0}^{k_{i}-1}\left(\begin{array}{c}K_{i} \\ y\end{array}\right) \zeta^{y}(1-\zeta)^{K_{i}-y}$.

Any $p$ value below a significance level $\alpha$ indicates occurrence of a damage event, as it is unlikely to be associated 
with non-rainfall-related claims. Different levels of significance $\left(\alpha=1 \times 10^{-2}, 1 \times 10^{-3}, 1 \times 10^{-4}\right.$ and $\left.1 \times 10^{-5}\right)$ are used to study its effect on the results. A binary variable $Y_{i}$ is introduced to classify the observations that are considered a damage event $Y_{i}=1$ and those that are not $Y_{i}=0$ :

$Y_{i}= \begin{cases}1 & \text { if } p \text { value }<\alpha \\ 0 & \text { if } p \text { value } \geq \alpha .\end{cases}$

\subsection{Linking binary outcome to maximum rainfall intensity}

The outcome, damage event or not, can be linked to the maximum rainfall intensity (maximum within one day for the chosen time window $z$ ) using various types of models for binary data (McCullagh and Nelder, 1989). In this study a logistic function was used, which yields

$\operatorname{logit}\left(\theta_{i}\right)=\log \left(\frac{\theta_{i}}{1-\theta_{i}}\right)=\beta_{0}+\beta_{1} I_{z, i}$,

where $\theta_{i}$ is the probability of a damage event $\left(Y_{i}=1\right)$ and $\beta_{0}$ and $\beta_{1}$ are regression coefficients. The regression coefficients are estimated using maximum likelihood estimation. The likelihood ratio (LR) test is used to test if $\beta_{1}$ is significantly different from zero, i.e. if maximum rainfall intensity is a parameter that contributes to high numbers of damage claims. There is no universally accepted goodness-of-fit measure in logistic regression that represents the proportion of variance explained by the predictors, such as $R^{2}$ in ordinary least squares regression. Several pseudo- $R^{2}$ statistics have been developed that mimic the $R^{2}$ in evaluating the variability explained, which is one of the approaches used in this study. In this study McFadden's $R^{2}$ is used, which compares the log-likelihood of the model without predictor and log-likelihood of the model with predictor (Long, 1997, p. 104). The other approach directly compares observed and predicted values from the fitted model using contingency tables, using a cutoff point of $\theta=0.5$.

\section{Results}

\subsection{Logistic regression results}

In Table 4 the results of the logistic regression are summarized. Results are based on the 60-min rainfall intensity. The significance levels $\alpha$, used for the dichotomization of damage data, range from $1 \times 10^{-2}$ to $1 \times 10^{-5}$. Table 4 lists estimates for slope coefficient $\beta_{1}$, since this is the most important parameter for interpretation of logistic regression results. The standard error in $\beta_{1}$ is denoted as SE. The slope coefficient is expressed in exponential form, $\exp \left(\beta_{1}\right)$, which is the odds ratio. The odd ratio should be interpreted as the factor with which the odds (probability of a damage event divided by probability of no damage) change as an effect one unit change in the maximum rainfall intensity. For a large number of observations, $\mathrm{LR} \sim \chi^{2}$ with degrees of freedom equal to the number of parameters being estimated.

The slope coefficient is significantly different from zero in all cases (at $p<0.05$ level), which means the maximum rainfall intensity is a significant predictor for the probability of occurrence of rainfall-related damage. The odd ratios $\left(\exp \left(\beta_{1}\right)\right)$ vary between $1.28-1.35$ for property damage and $1.26-1.30$ for content damage, indicating a $28-35 \%$ (property) and $26-30 \%$ (content) increase in odds of a damage event for each $\mathrm{mmh}^{-1}$ change in rainfall intensity. Different time windows between $10 \mathrm{~min}$ and $4 \mathrm{~h}$ have been investigated and produce similar results.

In Fig. 3 four examples of logistic functions are plotted as well as the data on which models were fitted. The plots are related to cases of property damage (with the dichotomization based on $\alpha=1 \times 10^{-3}$ ) and 10-, 20-, 30- and 90-min rainfall intensities. The function links the probability of a damage event $\theta$ on the $y$-axis to maximum rainfall intensity $I_{z}$ on the $\mathrm{x}$-axis. The steepness of the slope of the logistic function is determined by $\beta_{1}$ (see also Table 4); a large slope coefficient makes the transition between "low damage" and "damage event" more abrupt. The grey dots are the observations, either $Y=0$ in case of "low damage" or $Y=1$ in case of a "damage event". A jitter function was applied to better visualize the density of the data points. The open circles are the calculated empirical proportions (number of observed $Y=1$ in a bin divided by total number of observations in a bin $n$ ) for eight non-overlapping equally sized bins. The error bars represent one standard deviation $\sigma$ of uncertainty on the empirical proportion estimate, where $\sigma=\sqrt{\theta(1-\theta) / n}$.

Most observations without damage $(Y=0)$ are associated with low-intensity rainfall; e.g. $99 \%$ of the observations without damage are below $6.9 \mathrm{~mm}$ in $10 \mathrm{~min}$. Few observations of low damage are associated with high-intensity rainfall. The $Y=1$ observations are distributed over a larger range of rainfall intensities. The differences in the distributions of $Y=0$ and $Y=1$ are also reflected in the empirical proportions (open circles), with increasing values for higher rainfall intensities. Due to the low number of observations for high rainfall intensities, large uncertainty ranges occur for values of $\theta>0.5$.

\subsection{Goodness-of-fit using pseudo- $R^{2}$}

McFadden's $R^{2}$ statistic was calculated using different time windows $(z)$ and thresholding criteria $(\alpha)$. Results are listed in Table 5. The maximum rainfall intensity accounts for at most $34 \%$ (for property damage) and at most $30 \%$ (for content damage) of the variance explained, taking into account that these values are approximations and depend on the selected pseudo- $R^{2}$. There is a slight improvement in the model predictability if rainfall intensity is based on longer time windows, with an "optimum" between 2 and $4 \mathrm{~h}$. The differences are, however, rather small to be conclusive about 
Table 4. Logistic regression results for model fits on property and content data. The results are based on $z=60$ min and a range of $\alpha$ levels. The regression coefficient $\beta_{1}$ has units in $\mathrm{h} \mathrm{mm}^{-1}$.

\begin{tabular}{|c|c|c|c|c|c|c|c|c|c|}
\hline \multirow[b]{2}{*}{ data } & \multirow[b]{2}{*}{$\alpha$} & \multirow[b]{2}{*}{$\beta_{1}$} & \multirow[b]{2}{*}{ SE } & \multirow[b]{2}{*}{ LR } & \multirow[b]{2}{*}{ d.f. } & \multirow[b]{2}{*}{$p$} & \multirow[b]{2}{*}{$\exp \left(\beta_{1}\right)$} & \multicolumn{2}{|c|}{$95 \%$ C.I. $\exp \left(\beta_{1}\right)$} \\
\hline & & & & & & & & Lower & Upper \\
\hline \multirow[t]{4}{*}{ property } & 0.01 & 0.265 & 0.0093 & 766 & 1 & $<0.001$ & 1.30 & 1.28 & 1.33 \\
\hline & 0.001 & 0.309 & 0.0113 & 723 & 1 & $<0.001$ & 1.36 & 1.33 & 1.39 \\
\hline & 0.0001 & 0.319 & 0.0126 & 626 & 1 & $<0.001$ & 1.38 & 1.34 & 1.41 \\
\hline & 0.00001 & 0.325 & 0.0141 & 528 & 1 & $<0.001$ & 1.38 & 1.35 & 1.42 \\
\hline \multirow[t]{4}{*}{ content } & 0.01 & 0.248 & 0.0081 & 882 & 1 & $<0.001$ & 1.28 & 1.26 & 1.30 \\
\hline & 0.001 & 0.281 & 0.0097 & 782 & 1 & $<0.001$ & 1.32 & 1.30 & 1.35 \\
\hline & 0.0001 & 0.276 & 0.0107 & 597 & 1 & $<0.001$ & 1.32 & 1.29 & 1.35 \\
\hline & 0.00001 & 0.282 & 0.0118 & 516 & 1 & $<0.001$ & 1.33 & 1.30 & 1.36 \\
\hline
\end{tabular}
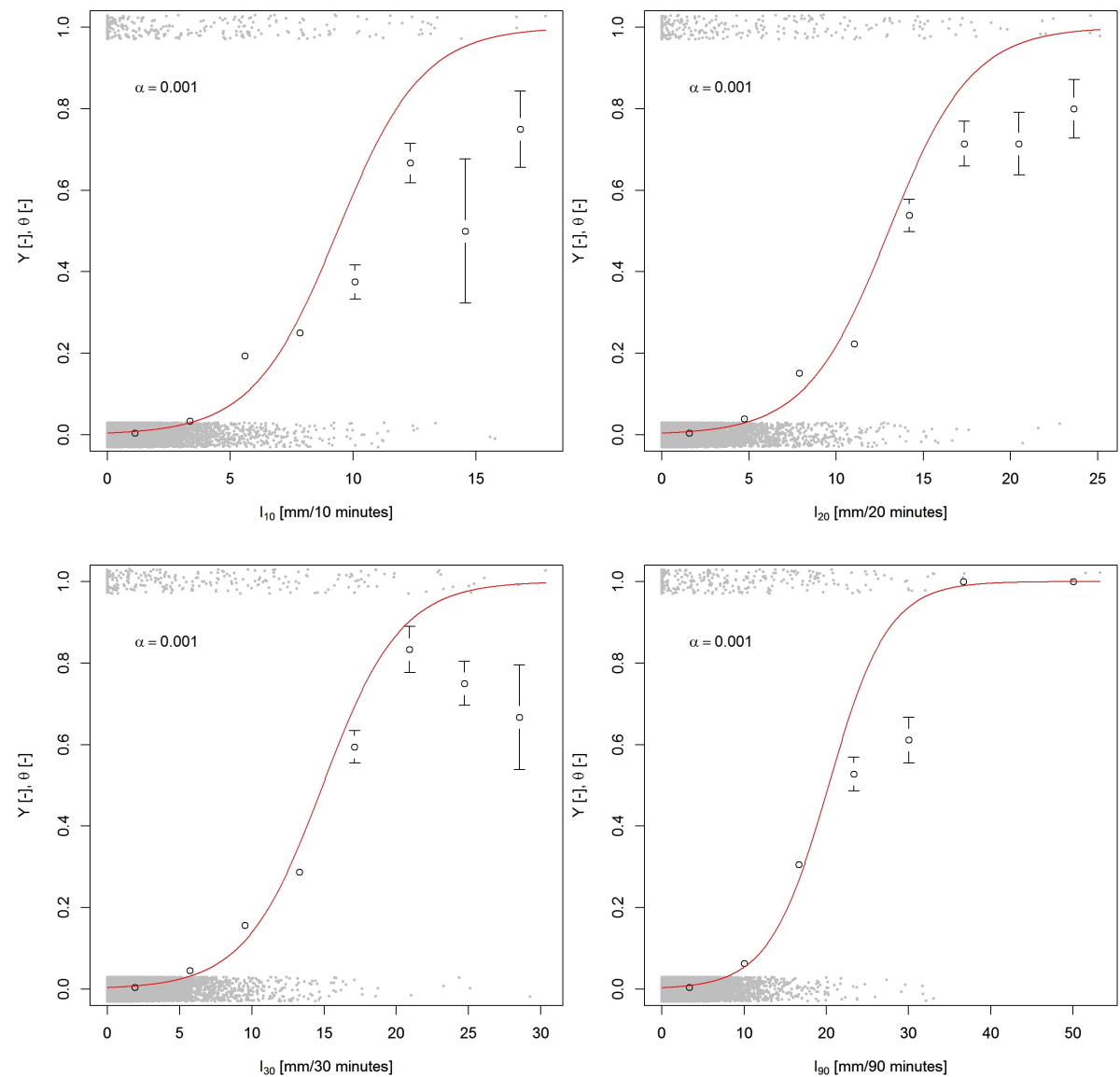

Fig. 3. Logistic functions (solid lines) fitted on property damage data. Plots are related to the cases of $z=10,20,30$ and 90 , using $\alpha=$ $1 \times 10^{-3}$. The grey small dots are the binary observations, either $Y=0$ or $Y=1$. A jitter function was applied on the binary observations to better visualize the density of the data points. The open circles are the calculated empirical proportions for eight non-overlapping, equally sized bins. The error bars represent one standard deviation of uncertainty on the empirical proportion estimate.

what time window best predicts damage. An optimum, if true, may reflect the temporal scale at which failure mechanisms (e.g. floodings, leakages of roofs) have caused damage. It would be interesting to have more detailed information on the cause of a damage claim, which would possibly allow characterising temporal scales of different damage generating mechanisms. The results suggest that for this kind of analysis there is no need to collect rainfall data with temporal resolutions smaller than $10 \mathrm{~min}$. Lowering the significance level $\alpha$, and hence selecting observations that are related to a larger number of claims, improves the predictability by high rainfall intensities. In other words, the results 
Table 5. Evaluation of model performance using McFadden's $R^{2}$. Outcomes are given for ranges of $z$ and $\alpha$.

\begin{tabular}{|c|c|c|c|c|c|c|c|c|c|c|c|c|}
\hline & & $z=10$ & $z=20$ & $z=30$ & $z=40$ & $z=50$ & $z=60$ & $z=90$ & $z=120$ & $z=180$ & $z=240$ & $z=480$ \\
\hline \multirow[t]{4}{*}{ property } & $\alpha=0.01$ & 0.102 & 0.111 & 0.114 & 0.117 & 0.118 & 0.120 & 0.123 & 0.124 & 0.126 & 0.127 & 0.126 \\
\hline & $\alpha=0.001$ & 0.186 & 0.205 & 0.212 & 0.215 & 0.218 & 0.220 & 0.224 & 0.228 & 0.230 & 0.227 & 0.222 \\
\hline & $\alpha=0.0001$ & 0.234 & 0.255 & 0.263 & 0.268 & 0.273 & 0.275 & 0.277 & 0.278 & 0.280 & 0.275 & 0.269 \\
\hline & $\alpha=0.00001$ & 0.280 & 0.305 & 0.314 & 0.323 & 0.329 & 0.331 & 0.335 & 0.339 & 0.344 & 0.340 & 0.333 \\
\hline \multirow[t]{4}{*}{ content } & $\alpha=0.01$ & 0.092 & 0.099 & 0.103 & 0.107 & 0.109 & 0.110 & 0.114 & 0.116 & 0.118 & 0.116 & 0.110 \\
\hline & $\alpha=0.001$ & 0.167 & 0.177 & 0.183 & 0.189 & 0.192 & 0.195 & 0.202 & 0.207 & 0.212 & 0.210 & 0.196 \\
\hline & $\alpha=0.0001$ & 0.190 & 0.201 & 0.209 & 0.217 & 0.223 & 0.227 & 0.237 & 0.244 & 0.250 & 0.248 & 0.239 \\
\hline & $\alpha=0.00001$ & 0.232 & 0.244 & 0.256 & 0.266 & 0.272 & 0.277 & 0.285 & 0.292 & 0.298 & 0.294 & 0.284 \\
\hline
\end{tabular}

Table 6. Rainfall thresholds: rainfall intensity in $\mathrm{mm} \mathrm{h}^{-1}$ for time window $z$ at which probability of a damage event $\theta=0.5$.

\begin{tabular}{llccccccccccc}
\hline & & $z=10$ & $z=20$ & $z=30$ & $z=40$ & $z=50$ & $z=60$ & $z=90$ & $z=120$ & $z=180$ & $z=240$ & $z=480$ \\
\hline \multirow{2}{*}{ property } & $\alpha=0.01$ & 52.2 & 36.3 & 27.8 & 22.7 & 19.3 & 17.0 & 12.6 & 10.3 & 7.8 & 6.4 & 4.0 \\
& $\alpha=0.001$ & 56.2 & 39.1 & 29.8 & 24.4 & 20.8 & 18.2 & 13.5 & 10.9 & 8.2 & 6.8 & 4.3 \\
& $\alpha=0.0001$ & 60.1 & 42.0 & 32.1 & 26.2 & 22.2 & 19.4 & 14.5 & 11.8 & 8.8 & 7.3 & 4.6 \\
& $\alpha=0.00001$ & 64.5 & 45.2 & 34.6 & 28.2 & 23.9 & 20.9 & 15.6 & 12.5 & 9.3 & 7.7 & 4.8 \\
\hline \multirow{2}{*}{ content } & $\alpha=0.01$ & 56.3 & 39.4 & 30.1 & 24.5 & 20.8 & 18.2 & 13.5 & 10.9 & 8.2 & 6.8 & 4.4 \\
& $\alpha=0.001$ & 60.8 & 43.1 & 33.2 & 27.0 & 22.8 & 20.0 & 14.7 & 11.9 & 8.8 & 7.2 & 4.6 \\
& $\alpha=0.0001$ & 67.8 & 48.4 & 37.3 & 30.3 & 25.7 & 22.4 & 16.5 & 13.2 & 9.8 & 8.0 & 5.0 \\
& $\alpha=0.00001$ & 71.6 & 51.2 & 39.6 & 32.2 & 27.2 & 23.8 & 17.6 & 14.1 & 10.4 & 8.6 & 5.3 \\
\hline
\end{tabular}

indicate that observations related to a larger number of claims are more likely to be associated with rainfall data than observations related to a smaller number of claims. Property damage is better explained by rainfall than content damage, although the differences are marginal (1-4\% point).

\subsection{Goodness-of-fit using contingency table}

Another way to look at model performance is to directly compare observed and predicted values using contingency tables. The model is said to have predicted a significant damage event if the estimated $\theta$ is greater than or equal to 0.5 and no damage if $\theta$ is smaller than 0.5 . The rainfall intensity for which the probability of success equals 0.5 is here defined as the rainfall threshold, although it does not necessarily imply a sudden transition from "no damage" to "damage". The rainfall thresholds are listed in Table 6 for different $\alpha$ and $z$. The thresholds are slightly higher for lower significance levels and higher for content damage compared to property damage; however, these differences are small compared to uncertainty introduced by assuming gauge measurement to be representative for the area in a $10-\mathrm{km}$ range of the rain gauge.

In a $2 \times 2$ contingency table the observed $Y(0-$ no damage observed or 1 - damage observed) is compared with the predicted $Y(0-$ no damage predicted or $1-$ damage predicted $)$. Table 7 presents the contingency table for $\alpha=1 \times 10^{-5}$ and $z=60$ based on property damage data. The percentage of correct predictions $\left(=\frac{a+d}{n}=0.997\right)$ is heavily skewed in this
Table 7. Contingency table, cutoff point $\theta=0.5\left(\alpha=1 \times 10^{-5}, z=\right.$ 60 , property data).

\begin{tabular}{lrrr}
\hline & $\begin{array}{r}\text { Damage predicted } \\
I_{z} \geq 20.9\end{array}$ & $\begin{array}{r}\text { No damage predicted } \\
I_{z}<20.9\end{array}$ & Total \\
\hline Damage observed & $a=19$ & $b=101$ & 120 \\
No damage observed & $c=13$ & $d=34056$ & 34069 \\
\hline Total & 32 & 34157 & $\mathrm{n}=34189$ \\
\hline
\end{tabular}

case due the high number of days without damage. An alternative performance index, less sensitive to skewness of observations, is the sum of fractions of correctly predicted observations $\left(=\frac{a}{a+b}+\frac{d}{c+d}\right)$ (Kennedy, 2003). Using this approach, scores are presented in Table 8 for a range of $z$ and $\alpha$. The models score around 5-17\% better compared to random predictions. In most cases, property damage is better predicted by rainfall than content damage, although the differences are small and for a few cases scores are equal. The scores do not improve when lowering the significance level from $1 \times 10^{-4}$ to $1 \times 10^{-5}$. The highest scores are obtained for time windows between 30 and $50 \mathrm{~min}$, which are smaller than the 2 to $4 \mathrm{~h}$ found using McFadden's $R^{2}$.

\section{Discussion}

The contingency tables can be used to address the fractions of type 1 errors and type 2 errors. Type 1 errors ( $b$ in Table 7$)$ 
Table 8. Scores using alternative performance index $\left(=\frac{a}{a+b}+\frac{d}{c+d}\right)$.

\begin{tabular}{llccccccccccc}
\hline & & $z=10$ & $z=20$ & $z=30$ & $z=40$ & $z=50$ & $z=60$ & $z=90$ & $z=120$ & $z=180$ & $z=240$ & $z=480$ \\
\hline \multirow{2}{*}{ property } & $\alpha=0.01$ & 1.05 & 1.07 & 1.07 & 1.07 & 1.07 & 1.08 & 1.07 & 1.07 & 1.07 & 1.07 & 1.06 \\
& $\alpha=0.001$ & 1.08 & 1.13 & 1.14 & 1.14 & 1.14 & 1.12 & 1.12 & 1.11 & 1.10 & 1.10 & 1.10 \\
& $\alpha=0.0001$ & 1.11 & 1.16 & 1.17 & 1.16 & 1.16 & 1.15 & 1.15 & 1.14 & 1.13 & 1.11 & 1.12 \\
& $\alpha=0.00001$ & 1.11 & 1.15 & 1.17 & 1.16 & 1.16 & 1.16 & 1.16 & 1.16 & 1.13 & 1.14 & 1.12 \\
\hline \multirow{2}{*}{ content } & $\alpha=0.01$ & 1.04 & 1.05 & 1.06 & 1.06 & 1.07 & 1.07 & 1.06 & 1.06 & 1.07 & 1.06 & 1.05 \\
& $\alpha=0.001$ & 1.07 & 1.09 & 1.11 & 1.10 & 1.10 & 1.10 & 1.11 & 1.11 & 1.11 & 1.10 & 1.08 \\
& $\alpha=0.0001$ & 1.06 & 1.08 & 1.10 & 1.12 & 1.12 & 1.12 & 1.14 & 1.12 & 1.13 & 1.12 & 1.10 \\
& $\alpha=0.00001$ & 1.07 & 1.07 & 1.09 & 1.11 & 1.13 & 1.12 & 1.12 & 1.14 & 1.14 & 1.12 & 1.12 \\
\hline
\end{tabular}

can be indicative of local rainfall that caused damage, while it was not recorded by the local rain gauge due to insufficient spatial density of the rain gauge network. They can also indicate that rainfall intensity does not sufficiently represent the damage generating mechanism and that other exploratory variables such as total rainfall volume, wind speeds or building characteristics need to be added to the model. Type 2 errors ( $c$ in Table 7) can be related to local rainfall that hit the rain gauge, but not the surrounding urban area. They can also be related to cases of overnight rainfall where people claim the day after. The time window approach used in this study allowed rainfall intensity to be based on rainfall prior to midnight; still rainfall that fell before the start of the time window was not analysed. Both types of errors could be reduced with a higher spatial resolution of rainfall data. Weather radar data are able to provide a better representation of spatial variability, although it is less accurate in determining the intensity than gauge measurements.

The need to reduce type 1 and type 2 errors can be different for different stakeholders. As an example from the water manager's perspective, a decision to open or not to open a water storage facility may lead to unpreparedness in case of a type 1 error or unnecessary costs in case of a type 2 error. A more risk-seeking attitude (accepting some damage) of a potential decision-maker allows a larger cutoff point $(\theta>0.5)$, and a more risk-averse attitude (accepting no damage) allows a smaller cutoff point $(\theta<0.5)$.

A considerable fraction of the variance is left unexplained, which emphasizes the need to study other explanatory variables. There are a few aspects that need to be considered when taking other explanatory factors into account: (1) the explanatory variable should be available and parameterized at the level of 4-position districts, as this is the scale at which insurance data are available; (2) data should be available nationwide if the analysis is performed on the whole insurance database; and (3) since additional data come from different sources, different levels of data quality need to be taken into account. Explanatory factors that are worthwhile to investigate in a future study are topographical properties, urban drainage system properties (e.g. drainage capacity, age of infrastructure, percentage of surface water), level of urbanization, socio-economic indices (e.g. income of households, property value), and district properties (e.g. percentages of low-rise and high-rise buildings, percentage impervious surface).

The results of this study are of practical relevance for insurers, water managers and meteorologists. Some insurers have indicated that the staffing of their call centres (that receive the claims) during extreme events is an issue, and that a better knowledge of what events are likely to cause considerable calls (tens of times more than on a regular day) can be helpful to adjust the capacity of their call centres. It can also be relevant for insurers when reconsidering their policy conditions. The current "rainfall clause" that is being used (see Sect. 2.2) has some flaws. For example, the rainfall intensity criteria that are mentioned in this clause are not related to capacities of urban drainage systems. Dutch urban drainage systems are designed to cope with $21.6 \mathrm{~mm} \mathrm{~h}^{-1}$; the " $40 \mathrm{~mm}$ in $24 \mathrm{~h}$ " criterion, for example, normally should not cause sewer flooding. The results of this study show that short-duration intense rainfall already results in a significant number of claims. Another interesting application is the development or validation of weather alarms, which are usually based on some meteorological thresholds. Climate researchers may use the model to extrapolate probabilities of rainfall damage given some projected change in rainfall extremes.

The extent to which the available insurance data can be used for pluvial flood damage models is limited for two main reasons. First, it is hard to distinguish those claims that are related to pluvial floods from those claims related to other failure mechanisms (e.g. leakages of roofs). Insurers use different definitions for pluvial flooding and different systems to categorize claims. A better and more systematic documentation of claim data could overcome this problem. Second, the building addresses are available at the level of 4-position districts (i.e. neighbourhoods), and therefore it is impossible to relate claims to attributes of individual households, such as the level of precaution, basement use and door threshold level. Simplified damage assessment may be possible at the level of neighbourhoods, taking into account districtspecific properties. 


\section{Conclusions and recommendations}

This study investigated relationships between water-related damage data from insurance companies and rainfall extremes for the period of 2003-2009 in the Netherlands. The results show that high claim numbers related to private property and content damages were significantly related to maximum rainfall intensity, based on a logistic regression, with rainfall intensity for $10-\mathrm{min}$ to 4 -h time windows. The variance explained by rainfall intensity, approximated by a pseudo- $R^{2}$ statistic, was at most $34 \%$ for property damage and at most $30 \%$ for content damage, depending on the selected time window. When directly comparing predicted and observed values, the model was able to predict $5-17 \%$ more cases correctly compared to a random prediction. No important differences were found between property and content damage data. A considerable fraction of the variance is left unexplained, which emphasizes the need to study damage generating mechanisms and other explanatory variables, such as total rainfall volume, wind speed or building characteristics. For simplified flood risk assessment, it could be of interest to use the insurance database to investigate relationships between the total damage of all damaged buildings and rainfall characteristics. There is also a need for high-resolution rainfall data at the urban scale to have better spatial linkages between rainfall and claim data. A better documentation of exact damage causes in insurance databases is essential to detail relationships with damages caused by failure mechanisms of urban drainage systems.

Acknowledgements. This work has been funded by the EU 7th Framework Programme project Smart Resilience Technology, Systems and Tools (SMARTeST 2010-2012). The authors would like to thank the Dutch Association of Insurers and Royal Netherlands Meteorological Institute for their support and making available the data.

Edited by: F. Pappenberger

\section{References}

Berne, A., Delrieu, G., Creutin, J.-D., and Obled, C.: Temporal and spatial resolution of rainfall measurements required for urban hydrology, J. Hydrol., 299, 166-179, 10.1016/j.jhydrol.2004.08.002, 2004.

Blanc, J., Hall, J., Roche, N., Dawson, R., Cesses, Y., Burton, A., and Kilsby, C.: Enhanced efficiency of pluvial flood risk estimation in urban areas using spatial-temporal rainfall simulations, J. Flood Risk Manage., doi:10.1111/j.1753-318X.2012.01135.x, 2012.

Coulthard, T. and Frostick, L.: The Hull floods of 2007: implications for the governance and management of urban drainage systems, J. Flood Risk Manage., 3, 223-231, doi:10.1111/j.1753318X.2010.01072.x, 2010.

De Moel, H. and Aerts, J. C. J. H.: Effect of uncertainty in land use, damage models and inundation depth on flood damage es- timates, Nat. Hazards, 58, 407-425, doi:10.1007/s11069-0109675-6, 2011.

Douglas, I., Garvin, S., Lawson, N., Richards, J., Tippett, J., and White, I.: Urban pluvial flooding: a qualitative case study of cause, effect and nonstructural mitigation, J. Flood Risk Manage., 3, 112-125, doi:10.1111/j.1753-318X.2010.01061.x, 2010.

Elmer, F., Seifert, I., Kreibich, H., and Thieken, A. H.: A delphi method expert survey to derive standards for flood damage data collection, Risk Analysis, 30, 107-124, doi:10.1111/j.15396924.2009.01325.x, 2010.

Ernst, J., Dewals, B., Archambeau, P., Detrembleur, S., Erpicum, S., and Pirotton, M.: Integration of accurate 2D inundation modelling, vector land use database and economic damage evaluation, in: Flood Risk Management: Research and Practice, Proceedings of the European Conference on Flood Risk Management - Flood Risk 2008, Balkema, Rotterdam, 1643-1653, 2008.

Falconer, R. H., Cobby, D., Smyth, P., Astle, G., Dent, J., and Golding, B.: Pluvial flooding: new approaches in flood warning, mapping and risk management, J. Flood Risk Manage., 2, 198-208, doi:10.1111/j.1753-318X.2009.01034.x, 2009.

Freni, G., La Loggia, G., and Notaro, V.: Uncertainty in urban flood damage assessment due to urban drainage modelling and depthdamage curve estimation, Water Sci. Technol., 61, 2979-2993, 2010.

Hurford, A. P., Parker, D. J., Priest, S. J., and Lumbroso, D. M.: Validating the return period of rainfall thresholds used for Extreme rainfall alerts by linking rainfall intensities with observed surface water flood events, J. Flood Risk Manage., 5, 134-142, doi:10.1111/j.1753-318X.2012.01133.x, 2012a.

Hurford, A. P., Priest, S. J., Parker, D. J., and Lumbroso, D. M.: The effectiveness of extreme rainfall alerts in predicting surface water flooding in England and Wales, Int. J. Climatol., 32, 1768-1774, doi:10.1002/joc.2391, 2012b.

Jak, M. and Kok, M.: A database of historical flood events in the Netherlands, in: Flood Issues in Contemporary Water Management, NATO Science Series 2, Environmental Security, Kluwer Academic Publisher, The Netherlands, 139-146, 2000.

Jonkman, S. N., Bockarjova, M., Kok, M., and Bernardini, P.: Integrated hydrodynamic and economic modelling of flood damage in the Netherlands, Ecol. Econ., 66, 77-90, doi:10.1016/j.ecolecon.2007.12.022, 2008.

Kennedy, P.: A Guide to Econometrics, MPG Books, 5th Edn., Bodmin, Cornwall, 2003.

KNMI: Handbook for the meteorological observation. Chapter 6: Precipitation, Tech. rep., KNMI, De Bilt, Netherlands, available at: http://www.knmi.nl/samenw/hawa/pdf/Handbook_H01_H06. pdf (last access: 1 August 2012), 2000.

Long, J. S.: Regression Models for Categorical and Limited Dependent Variables, Sage Publications, Thousand Oaks, USA, 1997.

McCullagh, P. and Nelder, J.: Generalized Linear Models, 2nd Edn., Chapman and Hall, Chicago \& London, 1989.

Merz, B., Kreibich, H., Thieken, A., and Schmidtke, R.: Estimation uncertainty of direct monetary flood damage to buildings, Nat. Hazards Earth Syst. Sci., 4, 153-163, doi:10.5194/nhess-4-1532004, 2004.

Middelmann-Fernandes, M.: Flood damage estimation beyond stage-damage functions: an Australian example, J. Flood Risk Manage., 3, 88-96, doi:10.1111/j.1753-318X.2009.01058.x, 2010. 
Ministry of Transport, Public Works and Water Management: Insurability of damages related to extreme rainfall and pluvial flooding, Tech. rep., RIZA, Lelystad, The Netherlands, 2003.

Overeem, A., Leijnse, H., and Uijlenhoet, R.: Measuring urban rainfall using microwave links from commercial cellular communication networks, Water Resour. Res., 47, 1-16, 10.1029/2010WR010350, 2011.

Parker, D., Priest, S., and McCarthy, S.: Surface water flood warnings requirements and potential in England and Wales, Appl. Geogr., 31, 891-900, doi:10.1016/j.apgeog.2011.01.002, 2011.

Pistrika, A. K. and Jonkman, S. N.: Damage to residential buildings due to flooding of New Orleans after hurricane Katrina, Nat. Hazards, 54, 413-434, doi:10.1007/s11069-009-9476-y, 2009.

Pitt, M.: Learning lessons from the 2007 floods, and independent review by Sir Michael Pitt, The Pitt Review Cabinet Office, London, UK, 2008.

Priest, S. J., Parker, D. J., Hurford, A. P., Walker, J., and Evans, K.: Assessing options for the development of surface water flood warning in England and Wales, J. Environ. Manage., 92, 30383048, doi:10.1016/j.jenvman.2011.06.041, 2011.

Ririassa, H. and Hoen, A.: Rainfall and damage: a study on relationships between rainfall and claims in relation to climate change, Tech. rep., Dutch Association of Insurers, The Hague, The Netherlands, 2010.
Statistics Netherlands: StatLine online database, available at: http: //statline.cbs.nl, last access: August 2012.

Ten Veldhuis, J. A. E.: How the choice of flood damage metrics influences urban flood risk assessment, J. Flood Risk Manage., 4, 281-287, doi:10.1111/j.1753-318X.2011.01112.x, 2011.

Thieken, A. H.: Methods for the documentation and estimation of direct flood losses, in: Urban Flood Risk Management Conference, edited by: Zenz, G. and Hornich, R., Graz, Austria, 2011.

Zhou, Q., Mikkelsen, P., Halsnæs, K., and Arnbjerg-Nielsen, K.: Framework for economic pluvial flood risk assessment considering climate change effects and adaptation benefits, J. Hydrol., 414-415, 539-549, doi:10.1016/j.jhydrol.2011.11.031, 2012a.

Zhou, Q., Petersen, T., Thorsen, B., and Arnbjerg-Nielsen, K.: Verification of flood damage modelling using insurance data, in: Proceedings of the Ninth International Conference on Urban Drainage Modelling, edited by: Prodanović, D. and Plavšić, J., Faculty of Civil Engineering, University of Belgrade, Belgrade, Serbia, 2012b. 